\title{
IDENTIFICATION OF MOSQUITO SPECIES IN DHAKA CANTONMENT
}

\author{
MD. RABIUL HOSSAIN', MD. SHAHIDULLAH, \\ NOZHAT NASREEN BANU ${ }^{2}$ AND MD. MEHDI HASAN JEWEL \\ 'Combined Military Hospital (CMH), Dhaka, Bangladesh \\ ${ }^{2}$ Armed Forces Medical College, Dhaka, Bangladesh
}

\begin{abstract}
The present study was carried out from 1st August 2011 to 31 January 2012 to identify mosquito species inhabiting in and around the Dhaka Cantonment. In all 5632 samples size were collected from 88 different spots. Important three genera such as Anopheles, Culex and Aedes were found and distribution was as Culex 5581 (99.09\%), Aedes 30 $(0.53 \%)$ and Anopheles $21(0.37 \%)$. Among the Culex species $C$. quinquefasciatus dominated and having $69.37 \%$ of Culex family. Other identified species were $C$. fuscocephala (14.89\%), C. tritaeniorhynchus $(09.07 \%)$ and C. vishmui $(06.67 \%)$. The sex distribution of the sampled mosquitoes revealed that female dominated and male female ratio was 34:66. There was predominance of $C$. quinquefasciatus in all collection points. Anopheles was identified 21 ( 12 female) in number of which $A n$. philipinensis was 17 and An. aconitus only 04 and they were collected from four spots of Zia colony and COD areas. Ae, aegypti was identified 30 (22 female) in number of which Ae aegyti were 23 and the rest 07 were Ae. albopictus and they were collected from seven spots of COD, Senapolli, Moinul Road and DOHS Mohakhali but its density is very insignificant and below the critical level of disease transmission.
\end{abstract}

Key words: Mosquito, Anopheles, Culex, Aedes, Dhaka Cantonment

\section{Introduction}

Correct identification of vector mosquitoes is essential for the effective control and prevention of some of the most dangerous tropical diseases: Malaria, Dengue, Japanese encephalitis, and Filariasis. The species of Bangladeshi mosquitoes incriminated in the transmission of each of the most important tropical diseases (Rattanarithikul and Prachong 1994). Historically, vector suppression has been viewed as a more economical and effective public health measure than medical therapy because it can be applied on a wide area basis without locating and treating each individual human patient (Macdonald 1960). There are no vaccines for malaria and drug prophylaxis of malaria has become increasingly difficult, specially in Southeast Asia. Identifying the vector is the first step in the control strategy for any arthropod borne diseases. Often, the simple knowledge that a vector species is present at a high density is sufficient to warn public health authorities that there has been an increase in the risk of transmission and that appropriate action should be planned (Rattanarithikul and Prachong 1994).

\footnotetext{
${ }^{1}$ Corresponding author: Email: rabiulhossain@msn.com
} 
A revised list had been presented which includes 113 species, including 34 anophelines and 79 culicines (Ahmed 1987a and 1987b. Currently 412 mosquito species are recognized, but most of them are of little practical significance in disease transmission, either because they are not biologically susceptible to human pathogens or, more usually, do not have habits that bring them into sufficient contact with man. Therefore, these keys identified only 34 species (Rattanarithikul and Prachong 1994).

Out of 34 Anopheles species recorded in Bangladesh, only 7 (seven) Spp. has been incriminatéd as malaria vector, these are: An. dirus, An minimus, An. philipinensis, An. sundaicus, An. aconitus, An. anularis, and An. vagus. The An. dirus and An. minimus are the main vectors in the forested hill and forest fringe areas. An. sundaicus is the main vector of coastal area of Cox's Bazar. An. Philipinensis is the main vector of plain rural areas. An. aconitus, An. anularis, and An. vagus are the main vector of the border belt epidemic prone areas. From recent entomological observation An. maculatus group is strongly suspected to be a new vector in certain areas of northern border districts (DGHS 2010).

The key issues in the present investigation have two intended purposes. First, although the mosquito fauna of Bangladesh has not yet been completely described, much of the work done during the last 30 years has appeared in scattered publications not readily available to field workers (Reinert 1990, Harrison et al. 1990 and Benjaphong et al. 1991). The Bionomics of the common mosquitoes of Dhaka and last checklist of the mosquitoes of Bangladesh were published 35 years ago (Ameen and Moizuddin 1973 and Ahmed 1987a and 1987b). Since that time no pragmatic research in this field had been carried out except few to collect pertinent information on all vector species prevailing in Bangladesh. The second purpose is to provide preventive medicine workers with a quick, accurate reference. The keys were designed to be used with intact specimens collected in Bangladesh. Southeast Asian users beyond the borders of Bangladesh should realize that the keys may not include all the medically important species in their countries.

Thus the present study aims to identify and classify the mosquito species according to prevalence in Dhaka Cantonment. Detection of such vectors might be crucial information to implement control measures for eradication. It will also facilitate the Medical and Health authority to achieve meaningful information about the causation of febrile illness in Dhaka Cantonment.

\section{Materials and Methods}

This study was carried out jointly by Infectious Disease Department of Combined Military Hospital $(\mathrm{CMH})$ Dhaka and Community Medicine of Armed Forces Medical College (AFMC). The mosquitoes were collected in the morning and evening between $600-700 \mathrm{hrs}$ and $1700-1800 \mathrm{hrs}$ from 88 different spots of Dhaka Cantonment including its surrounding bushy areas. The data collection period was from 1st Aug. 2011 to $31 \mathrm{Jan}$. 2012.

Mosquito collection, Instrument and procedures: The Instruments/ Equipments used for mosquito collection were mosquito aspirator with sucking tube. Afterwards the collected 
mosquitoes were transferred to paper cups, mosquito nets and test tubes by gently blowing for preservation. Cotton soaked in sugar solution was kept on netting which provided food for the captive insects.

Species, identification, procedures: The collected mosquitoes were sent to Community Medicine Departmental Laboratory of AFMC for identification. Insect collectors of SHO Dhaka Cantonment were engaged for collection of mosquito, its preservation and transportation. In the laboratory genera of mosquitoes which were identified by the naked eye subsequently were knocked down by using chloroform. These mosquitoes were then placed in the slides for mounting. In this case Balcon mount was used. All identified species were entered in the check list. The species was identified by entomologist of AFMC and the findings were subsequently confirmed by Entomologist of IEDCR. Manuals on medical entomology (Service 1996) were used to identify the mosquitoes at species level.

\section{Results and Discussion}

The study revealed that out of total 5632 mosquito specimens examined for identification of genus and species Culex species were 5581 (99.09\%), Aedes were $30(0.53 \%)$ and Anopheles were $21(0.37 \%)$ (Table 1$)$.

Table 1. Distribution of mosquitoes by genus.

\begin{tabular}{lcc}
\hline Generic names of mosquito & Number found & Percentage \\
\hline Anopheles & 21 & 0.37 \\
Culex & 5581 & 99.09 \\
Aedes & 30 & 0.53 \\
Total & 5632 & 100.00 \\
\hline
\end{tabular}

Sex distribution of mosquito revealed that males were $1892(33.59 \%)$ and the rest 3740 $(66.41 \%)$ were female. Male Female ratio was $34: 66$ approximately (Table 2).

Table 2. Distribution of mosquitoes by sex.

\begin{tabular}{ccccc}
\hline $\begin{array}{c}\text { Generic names } \\
\text { of mosquitoes }\end{array}$ & Male & Percentage & Fermale & Percentage \\
\hline Anopheles & 9 & 42.86 & 12 & 57.14 \\
Culex & 1875 & 33.60 & 3706 & 66.40 \\
Aedes & 8 & 26.67 & 22 & 73.33 \\
Total & 1892 & 33.59 & 3740 & 66.41 \\
\hline
\end{tabular}

Species distribution of Culex revealed that Culex quinquefasciatus occupied $69.37 \%$. Chronologically the other species are fuscocephala $14.89 \%$, tritaeniorhynchus $09.07 \%$ and vishnui $06.67 \%$ (Table 3). 
Species distribution of Aedes reveals that Ae. aegypti were 23 and the rest 07 were $A e$. albopictus. Similarly out of 21 Anopheles, An. Philiphinensis were 17 and the rest 04 were An. aconitus (Table 4).

Month wise distribution of mosquitoes shows that their density was the highest 1888 (33.52\%) in the month of November followed by August $1376(24.43 \%)$. (Table 5).

Species diversity of mosquitoes in Dhaka city has decreased from 27 species in 1970 to only 5 in 1997, but the population of quinquefasciatus has increased dramatically (Ameen et al. 1999). Its proportion in the total mosquito population of Dhaka city increased from $18.2 \%$ in 1970 to $57.2 \%$ in 1979 and $69.6 \%$ in 1997 (Ameen and Moizuddin 1973 and Ameen et al. 1982 and 1984 and Nazneen 1997) which is consistent with this study. Sex distribution shows predominance of female over male. Female male ratio was 66: 34 (Table 2). The findings are also consistent with the study of Ameen 1985, Nazneen 1997 and Russel et al. 1943.

Distribution of mosquitoes showed that more or less all collection spots having Culex, Aedes and Anopheles varieties. Culex was predominated i.e., $99.09 \%$ of the vector population among them quinquefasciatus occupying $69.37 \%$. Aedes mosquitoes were found only 30 out of 5632 collected samples and its percentage was only $0.53 \%$ of prevailing vector population. Aedes aegypti were collected from eight spots of general area of COD, Moinul road, Senapolli and DOHS mohakhali. Total 21 Anopheles mosquitoes were collected from general area of Zia colony and COD area. In all collection spots Culex was predominated i.e., $99.09 \%$ of the vector population among them quinquefasciatus occupying $69.37 \%$. Chronologically the other species occupying are fuscocephala $14.89 \%$, tritaeniorhynchus $09.07 \%$ and vishnui $06.67 \%$ (Table 3 ) and all the findings are consistent with the various studies of Bangladesh (Ameen et al. 1973 and 1999, Ameen 1985, and Elias et al.1987).

Table 3. Distribution of Culex species $(n=5581)$.

\begin{tabular}{lcc}
\hline Name of the species & Number & Percentage \\
\hline Cx.quinquefasciatus & 3872 & 69.37 \\
Cx.foscocephala & 831 & 14.89 \\
Cx.tritaeniorhynchus & 506 & 9.07 \\
Cx.vishnui & 372 & 6.67 \\
Total & 5581 & 100.00 \\
\hline
\end{tabular}

Aedes mosquitoes were found only 30 out of 5632 collected samples and its percentage was only $0.53 \%$ of prevailing vector population (Table 1 ). Among 30,22 were female and the remaining 8 were male (Table 2). The proportion of genus Aedes mosquitoes is very less $(0.53 \%)$ in contrast to the total number collected, which is much below than the critical level for disease transmission because the chance of man vector contact is very less. 
Amongst 21 , twelve were female and remaining were male. The identified species $A n$. Philipinensis were 17 and the rest 4 were An. aconitus. Similarly the genus Anopheles mosquitoes is also very less $(0.37 \%)$ in contrast to the total number collected which is much below than the critical level for disease transmission as a result the chance of man vector contact is also very less (Table 4).

Table 4. Distribution of Aedes and Anopheles species.

\begin{tabular}{llll}
\hline \multicolumn{1}{c}{$\begin{array}{c}\text { Generic names of } \\
\text { mosquitoes }\end{array}$} & \multicolumn{1}{c}{ Species } & Number & Percentage \\
\hline Aedes & Aedes aegypti & 23 & 0.40 \\
\multirow{2}{*}{ Anopheles } & Aedes Albopictus & 07 & 0.13 \\
& An. Philiphinensis & 17 & 0.30 \\
& An. Aconitus & 04 & 0.07 \\
\hline
\end{tabular}

Table 5. Month wise distribution of mosquitoes.

\begin{tabular}{lcc}
\hline Month & Number & Percentage \\
\hline August & 1376 & 24.43 \\
September & 1181 & 20.97 \\
October & 1187 & 21.08 \\
November & 1888 & 33.52 \\
Total & 5632 & 100.00 \\
\hline
\end{tabular}

Since the study was conducted for 6 months and data collection was limited for 4 months hence seasonal variation could not be analysed. Genus distribution shows that all genera were prevalent during monsoon (Table 6).

Table 6. Month wise distribution of mosquitoes by genus.

\begin{tabular}{lccccc}
\hline $\begin{array}{l}\text { Generic names } \\
\text { of mosquitoes }\end{array}$ & August & September & October & November & Total \\
\hline Culex & 1359 & 1168 & 1169 & 1885 & 5581 \\
Aedes & 14 & 05 & 08 & 03 & 30 \\
Anopheles & 03 & 08 & 10 & - & 21 \\
Total & 1376 & 1181 & 1187 & 1888 & 5632 \\
\hline
\end{tabular}

Genus distribution depicts that all genus were prevalent during monsoon.

Culex was prevalent throughout the study period but Aedes and Anopheles were prevalent during monsoon. The findings are consistent with studies of Ameen and Moizuddin and others (Ameen and Moizuddin 1973, Hossain and Elias et al. 1992 and Ameen et al. 1999). 


\section{References}

Ahmed, T. U. 1987a. Checklist of Mosquitoes of Bangladesh. Mosq Syst. 19(3):187-200.

Ahmed, T. U. 1987b. Checklist of the Mosquitoes of Bangladesh. Mosq. syst, 19(3): 191-204

Ameen, M. 1985. Mosquito menance of Dhaka city and environmental considerations in urban development. Proc. SARC seminar on protecting environment from Degradation, Dhaka:145-148.

Ameen, M. and M. Moizuddin. 1973. Bionomics of common Mosquitoes of Dacca. J nat Hist. 7: 121

Ameen, M., M. I. Hossain and M. D. H. Khan. 1982. Resting behaviour, bitting activity pattern and host preference of the common mosquitoes of Dhaka city. Bangladesh J Zool. 10: 35-48.

Ameen, M., M. I. Hossain and M. D. H. Khan. 1984. Seasonal prevalence of the common mosquitoes of Dhaka city. Dhaka Univ Stud B. 32: 79-89.

Ameen, M., M. I. Hossain and M. D. H. Khan. 1999. Integrated mosquito management in Dhaka city: Promising non-chemical components. Proceedings of the $3^{\text {rd }}$ International Conference on Urban Pests. Wm H. Robinson, F. Rettich and Rambo (editors).

Benjaphong, N. and R. Rattanarithikul. 1991. Zeugnomyia gracilis Leicester (Diptera: Culicidae), a new genus and species occurrence record from Thailand. Mosq Syst. 23: 53

Directorate General of Health Services (DGHS). 2010. Country paper of malaria and malaria control programme. Management Information System, Mohakhali, Dhaka, Bangladesh.

Elias, M., A. J. M. M. Rahman, M. M. Ali, J. Begum and A. R. Chowdhury. 1987. The ecology of malaria carrying mosquito anopheles philippinensis Ludlow and its relation to malaria in Bangladesh. BMRC Bull. 13(1):15-28.

Elias, M., N. P. Maheswary, A. M. Bangali, M. M. Hassan and H. Kabir. 1992. Review Article. Malaria in Bangladesh. Jopsom. Vol-II (2): 66-72.

Harrison, B. A., R. Rattanarithikul, E. L. Peyton and K. Mongkolpanya. 1990. Toxonomic changes, revised occurrence records and notes on the Culicidae of Thailand and neighbouring countries. Mosq Syst. 22: 196-227.

Macdonald, W. W. 1960. Malaysian parasites. Study Inst Med Res Malaya. 29:1-251.

Nazneen, S. 1997. Effects of impregnated curtains on the behaviour and mortality of mosquitoes in Dhaka city. M. Sc. Thesis, Dept. Zoology, Univ. Dhaka: 98 pp.

Rattanarithikul, R. and P. Prachong 1994. Illustrated keys to the medically important mosquitoes of Thiland. Southeast Asian J Trop Med Public Health. 25(1): 1-66.

Reinert, J. F. 1990. Medical entomology studies:XVII. Biosystematics of Kenknightia, A new subjenus of the mosquito genus Aedes Meigen from the Oriental Region. Contrib Am Entomology Inst (Ann Arbor). 26: 1-119.

Russel, P. F., L. E. Roseboom and A. Stone. 1943. Keys to Anopheline mosquitoes of the world with notes on their identification, distribution and biology in relation to malaria Philadelphia, Amer Entom Soc. 152.

Service, M.W. 1996. Medical Entomology for Students. Chapman \& Hall, London. 1-80. 